\title{
A Study on the Influence of Martial Art' entry into Colleges and Universities on the Employment Concepts of Students from Physical Education Department
}

\author{
Wenwen Wang \\ Nanchang Institute of Science \&Technology, Nanchang 330108, China
}

Keywords: fitness martial art; continuous promotion; employment prospects

\begin{abstract}
Martial art is being popularized in our country. In order to train more martial art talents and cater to fitness market's needs for professional talents, it is necessary to make use of higher education institutions and educational platforms to provide a good platform for more fitness martial art talents. It is especially necessary for colleges and universities to strengthen the training of martial art talents and to promote fitness martial art. Therefore, a more professional and systematic promotion is acquired. With the development of economy, people demand more and more for fitness martial art. Under the influence of the hot trend of national fitness, people demand more professional fitness martial art talents urgently. In our country, fitness martial art in colleges and universities has a good development prospect. In order to meet social needs as well as to promote employment rate, it is essential to constantly promote fitness martial art in colleges and universities.
\end{abstract}

With the development of economy, people pay more and more attention to fitness martial art. Especially with the improvement of material conditions, people also have a very strong desire and demand for a good physical health and life quality. In recent years, with the continuous development of national fitness, in order to satisfy the market's needs, many colleges and universities continuously promote fitness martial art. The college or university itself is the cradle of students' dream. In order to promote the progress of our society and the cultivation of high-quality talents, college students are taken as future successors. As a kind of leisure entertainment, fitness martial art plays a greater role in the construction of colleges and universities in our country. It has an indelible influence on physical education teaching in our country. Besides, more and more young people pursue fitness martial art urgently. At the same time, fitness martial art has a certain impact on the employment concepts of top students in many physical education in our country and plays a positive role to make college students engage in martial art fitness industry.

\section{Advantages of Training Fitness Martial Art Talents in Physical Education}

In our country's actual teaching process, especially in comprehensive normal physical education colleges, students can not only learn some physical knowledge in daily learning process, but also are able to select to learn some professional knowledge according to their own development conditions and future development requirements which is beneficial to their own development. It is also helpful to improve the comprehensive quality of students and cultivate all-round development talents. In order to enrich students' subject knowledge and promote their all-round development, physical education colleges have played a significant role in promoting the cultivation of fitness martial art talents.

With the continuous development of economy, colleges and universities in our country are constantly expanding enrollment. Along with the continuous development of employment forms, graduates of our comprehensive physical education colleges also have a certain impact on their development. Therefore, in order to broaden employment channels, students of comprehensive normal physical education colleges should be combined with the current social development needs and colleges are required to add some new majors suitable for the market development needs. According to the advantages of comprehensive physical education colleges and universities, this paper proposes a basic idea that fitness martial art talents in comprehensive physical education colleges should be given full play. Although China's comprehensive normal colleges have set up a 
traditional cultivation direction for fitness martial art talents, many colleges and universities still need to continue to explore innovation on the issue of how to train martial art fitness talents. Our comprehensive normal colleges must give full play to their advantages in the training of fitness martial art talents and accept more new teaching ideas as well as new teaching ideas for the construction and training of talents. At the same time, we should also pay attention to improve students' humanistic comprehensive literacy, strengthen teaching theories and teaching practice, and strive to establish an educational college with its own development characteristics in a short time. Only in this way, can we better adapt to the needs of social market.

\section{Necessity and Feasibility of Carrying out Fitness Martial Art in Physical Education}

Colleges and universities are also advised to explore continuously and adapt to the needs of modern education development when setting up fitness martial art curriculum. We must cultivate a kind of development which is in accordance with the reformation characteristics of physical education curriculum of colleges and universities as well as college students' sports values. At the end of 1998, the Ministry of Education issued "the Plan of Action for the Revitalization of Education in 21st Century" which means we need to carry out a comprehensive promotion for the overall quality education reform, especially to enhance our populace's cultivation and national innovation ability. By 2000, we should also initially form the standard and educational framework of modern basic education curriculum, the contents of the reform education and teaching methods. We are also supposed to continue to promote a new education system and evaluation standards. In particular, we should carry out teacher training and start new curriculum experiments. Although in the field of physical education in China, our educational thoughts have changed significantly to some extent, our educational thoughts are still based on the traditional educational thoughts. Problems that actually exist in physical education are: our education ignores the needs of students' development, only consider the development of society and tend to be indifferent to the development of students. Besides, the teaching contents are mostly empty, or even emphasize generalization and unification which often ignore the development of students' subjectivity. In many colleges and universities, teaching methods for middle school students are too single and too stylized. In summary, for professional physical education curriculum teaching, modern education concept still exists in the following aspects: firstly, in our actual teaching process, we are teaching dominated and students are the main body of receiving teaching. In the teaching, teachers need to give full play to the learning subjectivity of students. At the same time, we also must give play to students' leading role. Only to make teaching contents adapt to all students, can each student actively participate in teaching, which is helpful to cultivate their learning enthusiasm. Secondly, in our actual teaching process, we take a kind of cooperation cultivation, which reflects the importance of teamwork ability. Meanwhile, in the age of cooperative learning, it is a reflection of modern education concepts by making students actively participate in learning. Thirdly, there are individual differences among students and this individual difference itself is a kind of real and objective existence. Fully respecting the difference is the right attitude of confirming the existence of difference. Only if we treat the difference differently can students' subjectivity be given full play. Finally, our country has been promoting quality education. In the examination process, we treat traditional unified examinations differently. But our country always treats some students with comparatively poor foundation more cruelly. These students always obtain lower scores unceasingly in this kind of examinations. They feel inferiority in study which will exerts a negative impact on their learning, such as make them lose confidence in the future study and life. Successful experiences often lead to good psychological feelings, and at the same time, are also driving forces to enhance people's confidence and promote their learning.

In our country, fitness martial art has a profound historical and cultural background. As the largest branch of physical education colleges, fitness martial art has been quite popular among each nation in our country in early time. In order to meet the needs of the masses to participate in physical exercises and fitness, in recent years, in the sports circles of our country, after theoretical exploration and practice, we finally reached a certain consensus. According to "sports skills", 
"physical and mental health" and other target areas of "physical education and health curriculum standards", we promote the concepts of fitness martial art in colleges and universities. This regulation also reflected government's strong support for the subject of fitness martial art. The promoting process of fitness martial art in colleges and universities also wins the policy support for colleges of every province and city. Especially in recent years, normal physical education colleges and universities have set up related or similar physical education majors for fitness. But due to the faculty weakness, we suggest that some colleges and universities can choose or employ some outstanding graduates to act as a contingent of faculty, which will promote the development of college majors. Meanwhile, colleges and universities can also regularly send some excellent teachers with fitness experience to some foreign fitness institutions or the General Administration of Physical Education for fitness martial art certification training, or send them to some colleges famous with abundant fitness activities for visit and learning. At the same time, we can also hire a number of specialized fitness professionals or talents in health industry with fitness martial art experience. Besides, in order to solve our teacher problem, we may also employ these professionals as mentors to guide students in the teaching process. The fund problem can also be solved by various organizations, fitness martial art guidance and skills competition. As for the society and parents' lack of understanding for fitness martial art, it will be figured out through our propaganda.

Of course, we can not ignore the issue of venue. Some colleges with enough funds are able to increase the investment, especially for the continuous venue construction. While to solve the current site problem, some colleges with inadequate fund can also make the campus or some natural geographical environment as the venue.

In our country, we always adopt the traditional talent training mode to cultivate students from Physical Education College. We are still limited by faculty on the physical education cultivation which will undoubtedly make students face great employment pressure in the future. Although the number of majors in physical education colleges is obviously deficient, to some extent, it undoubtedly increases the choices of students and fitness martial art course is no doubt an attempt for colleges and universities. Therefore, we should adapt to the development of society and correspond with national fitness campaign. Only in this way, can we fundamentally change the students' needs of interests and at the same time offer students with a certain right to choose majors and learning autonomy. Fitness martial art course does not only enhance students' comprehensive abilities, but also provide a certain development needs for the all-round-development talents, so that more students are able to participate in physical education learning and more teachers will be led to actively carry out teaching activities of physical education. Thus, the development of the colleges is further advanced.

\section{Conclusion}

In our country, the cultivation of talents in many colleges and universities is limited within the traditional training and teaching methods. While the physical education major should support the concept of "health first" and offer more employment paths for students from physical colleges. Only in this way can we truly ensure that students from physical education colleges still keep a long lasting enthusiasm and perseverance after entering the society. Meanwhile, fitness martial art should have certain theoretical and practical experience for the development of colleges and universities. It can not only make students strengthen physical fitness when studying, but also let them have sports spirits and constantly enrich physical education curriculum resources. In order to make up for the deficiency of traditional physical education, since 21st century, the physical education of many colleges in our country has been changing constantly, which is the change of the times as well as the progress of our human civilization. Therefore, in the reform of many colleges and universities in our country, we should constantly improve the development of physical education major, make the courses offered by many colleges and universities conform to the social development and the market vacancy. 


\section{References}

[1] Lu Changfen, Wang Jie. On the Reform of Professional Curriculum System of Sports Training in China from the Perspective of Curriculum Reform of Physical Education Colleges and Universities in United States [J]. Journal of Xi'an Institute of Physical Education, 2003,20(1):96- 100.114

[2] Department of Science and Education of General Administration of Sports. General Situation of Physical Education of Foreign Colleges and Universities [M]. Beijing: People's Sports Publishing House, 1999:23-101.

[3] Ren Hai. Comparative Analysis of Curriculum Structure of Physical Education Colleges at Home and Abroad-the Second Probe into the Rationality of Curriculum Structure of Physical Education Colleges and Universities in China [J]. Journal of Shandong Sport University, 1998, 14(2):18.

[4] Xiang Shixin. A Comparative Study on Normal Physical Education of Undergraduate Education Between China and United States [J]. China Sport Science, 1997, 17(2):35—38. 